\title{
Physiotherapy management in patients with Covid-19
}

\author{
Clément Medrinal ${ }^{1,2,3}$, Yann Combret ${ }^{1,4}$, Tristan Bonnevie $^{5,6}$, Pauline Smondack ${ }^{6}$, Francis-Edouard Gravier ${ }^{5,6}$, Marius Lebret ${ }^{7}$ and \\ Guillaume Prieur ${ }^{1,4}$ \\ ${ }^{1}$ Groupe Hospitalier du Havre, Intensive Care Unit department and Pulmonology, avenue Pierre Mendes France 76290 Montivilliers, France., ${ }^{2}$ Université \\ Paris-Saclay, UVSQ, Erphan, 78000, Versailles, France., ${ }^{3}$ Institut de Formation en Masso-kinésithérapie Saint-Michel, 75015 Paris, France, ${ }^{4}$ Institut de \\ Recherche Expérimentale et Clinique (IREC), Pôle de Pneumologie, ORL \& Dermatologie, Groupe de Recherche en Kinésithérapie Respiratoire, Université \\ Catholique de Louvain, 1200 Brussels, Belgium., ${ }^{5}$ Normandie Univ, UNIROUEN, EA3830-GRHV, 76000 Rouen, France; Institute for Research and Innovation \\ in Biomedicine (IRIB), 76000 Rouen, France., ${ }^{6}$ ADIR Association, 76230 Bois-Guillaume, France., ${ }^{7}$ Institut Universitaire de Cardiologie et de Pneumologie de \\ Québec (IUCPQ), groupe de recherche en hypertension pulmonaire, 2725 Ch Ste-Foy, Québec, QC G1V 4 G5.
}

DOI: $10.52057 /$ erj.v1i1.2

received: 8 March 2021

accepted: 14 April 2021

\begin{abstract}
The coronavirus disease 2019 (COVID-19) is caused by the severe acute respiratory syndrome coronavirus 2 (SARS-CoV-2) which is responsible for the current pandemic and results in a large number of hospitalizations. This highly contagious disease causes severe acute respiratory infection; thus, many patients require management in intensive care. At a time when there is a high influx of patients with COVID-19 in Intensive Care Units all over the world, there is little literature concerning the physiotherapy management of these patients. This article provides information based on the latest evidence to help physiotherapists optimize care, to protect patients and care providers in the Intensive Care Units, and for follow-up care.
\end{abstract}

KEYWORDS: Covid-19; critically ill; intensive care unit; physiotherapy; rehabilitation

\section{Background}

The number of cases of SARS-CoV-2, responsible for the coronavirus 1 disease 2019 (COVID-19), rose at an exponential rate and rapidly reached the status of a pandemic. In a cohort from China, the COVID-19 was associated with severe disease requiring intensive care in approximately $5 \%$ of cases and the overall fatality rate was $2.3 \%$.The death rate for all infected patients may be in the range of $0.5 \%$ to $5.6 \%[1,2]$. Among patients requiring hospitalization, the proportion of case-fatalities is between $5 \%$ and $15 \%$. However, in patients who become critically ill, it ranges from $22 \%$ to $62 \%[3,4]$. From ICU to the recovery period, the interventions of physiotherapists are essential to prevent potential acquired muscle weakness and to improve the functional recovery of patients. The objective of this article is to recall the main functional consequences of hospitalization and to synthesize the possible actions (Figure 1). A section is also devoted to post-hospital care.

\section{Factors associated with admission to intensive care}

According to the latest available data, patients who require intensive care are older than patients who do not require intensive care (median age,

Corresponding author: Clément Medrinal, Groupe Hospitalier du Havre, ICU department, avenue Pierre Mendes France 76290 Montivilliers, France medrinal.clement.mk@gmail.com
66[57-78] years vs $51[37-62]$ years), and $72.2 \%$ have underlying comorbidities, commonly diabetes, respiratory and cardiac disease $[1,4]$. In a cohort study [5], death was associated with older age, a higher Sequential Organ Failure Assessment (SOFA) score, and d-dimer levels above $1.0 \mu \mathrm{g} / \mathrm{L}$ on admission. In this study, the median duration of viral shedding was 20 [17.0-24.0] days in survivors, but continued until death in fatal cases [5]. The most common symptoms on hospital admission were fever (94\%) and cough (79\%), followed by sputum production (23\%) and fatigue (23\%), which is concordant with the study by Yang et al. published early on [3].

Given the severe acute respiratory infection the disease causes, intensive care is a key component of the management. The median time between symptom onset and admission to the Intensive Care Unit (ICU) has been reported to be 9.5[7-12.5] days, suggesting a gradual deterioration in the majority of cases [3]. Two observational ICU studies showed that between $47 \%$ and $71 \%$ of patients admitted required invasive ventilation [3,4]. Non-survivors were more likely to develop Acute Respiratory Distress Syndrome (ARDS) compared to survivors and were more likely to need mechanical ventilation [3]. The most documented reason for requiring intensive care was for respiratory support, of which two-thirds of patients met the criteria for ARDS [4]. In addition to respiratory failure, sepsis and heart failure are also reported to be common reasons for admission to intensive care and subsequent intubation $[5,6]$. 


\section{Hygiene procedures for COVID-19 transmission control}

What is the risk of SARS-Cov-2 contamination for healthcare providers?

The risk of nosocomial transmission of SARS-Cov- 2 is high. One of the largest cohort reported revealed that a total of 1716 healthcare providers were contaminated out of 44672 confirmed cases of COVID-19. Around $15 \%$ of these cases were classified as severe or critical and five deaths occurred [1]. All care providers (including physiotherapists) that manage individuals with COVID-19 should therefore be thorough with their own protective measures, especially when providing aerosol-generating procedures. Moreover, contaminated care providers may also contaminate other patients. Another important point to consider is that the mean incubation period for SARS-Cov-2 infection is 5.2 days, but it can be up to 14 days [7]. If available, physiotherapists should wear surgical masks when taking care of other patients, or at least the most vulnerable ones, even if they have no signs of COVID-19 infection.

\section{What are the recommendations for the prevention and control of infection in care providers?}

One of the key components of infection prevention for the management of individuals with COVID-19 infection is staff education [8]. These measures involve taking precautions during all procedures that can generate aerosolization, droplets and contact. Personal Protective equipment (PPE) such as a surgical cap, a well-fitted high filtration mask (N95/FFP-2 masks), goggles or a face shield, a non-sterile, waterproof, long-sleeve gown and non-sterile gloves should be worn and at all times within the patient's room. A complete alcohol-based hand rub should be performed before, during and after dressing and undressing. All this equipment should be removed in the antechamber and treated as infectious waste (except for face shields and goggles). Comprehensive guidelines for dressing and undressing procedures have been published [8]. Protective measures for non-aerosol generating procedures can be limited to surgical masks, the use of gloves, gowns and goggles [9]. No personal belongings should be brought into the patient's room. Finally, all non-essential care procedures should be avoided to decrease the risk of viral transmission.

All therapists who are involved in aerosol-generating procedures and caring for patients on ventilatory support (Continuous positive airway pressure, Non-invasive Ventilation, High Flow Nasal Canula etc.) must use high levels of protection.

In the acute phase of a COVID-19 infection, caregivers should only enter the patient's room if their presence is essential, and they should be equipped with the appropriate level of PPE [10]. Aerosol's procedures should be applied with an awareness of the potential risks of contamination, and the aim of each intervention should be determined before entering the room (Figure 1). The Surviving Sepsis Campaign guidelines on the management of critically ill patients with COVID-19 suggested using a surgical/medical mask rather than a high filtration mask in addition to contact and eye protection during non-aerosol-generating procedures such as the prevention or treatment of complications relating to bed rest. This recommendation is applicable for both non-ventilated patients and those under invasive mechanical ventilation (closed circuit) [11]

\section{Clinical Management in the ICU and Outcomes}

The management of severe cases of COVID-19 is very close from the management of other types of viral pneumonia that cause respiratory failure. The principal feature of patients with severe disease is the development of ARDS that is characterized by a serious deterioration in gas exchange driven by alveolar and interstitial infiltrates [12]. Therefore, evidence-based treatment guidelines for ARDS should be followed, including conservative fluid strategies, antibiotic-therapy for potential bacterial co-infection, lung protective ventilation and prone positioning [13].

\section{Physiotherapy for patients on invasive mechanical ven- tilation}

\section{What are the consequences of mechanical ventilation?}

Approximately $50 \%$ of patients admitted to ICU develop ICU-acquired weakness, which may increase the duration of mechanical ventilation [14]. ICU-acquired weakness may also persist for up to 5 years after hospital discharge, with a significant loss of functional capacity [15]. The main contributors to ICU-acquired weakness are inflammation, metabolic disorders, and muscle rest during sedation or neuromuscular blockers, particularly in patients with sepsis and prolonged invasive mechanical ventilation [16, 17]. A high proportion of COVID-19 patients are on invasive ventilation (71\% of required mechanical ventilation in the cohort by Yang et al. [3]). It is therefore to be expected that the vast majority of these patients will develop ICU-acquired weakness. In addition to physical weakness, stays in ICU often result in cognitive and psychological impairments, which are collectively named post intensive care syndrome (PICS). There is a large body of evidence showing that muscle weakness is an independent factor associated with a higher rate of long-term mortality and a decrease in functional capacity $[18,19]$. A similar association has been found for PICS syndrome [20].

\section{How should muscle function be assessed in patients with COVID-19?}

Overall strength can be measured using the Medical Research Council sum-score (MRC-SS). ICU-acquired weakness is characterized by symmetrical impairment in the left and right limbs that is most prominent in proximal muscles [18]. A score below $48 / 60$ on the MRC scale indicates significant muscle weakness and is associated with an increase in the risk of ICU and hospital death [21].

As the diaphragm can be severely affected during controlled ventilation, the switch to spontaneous ventilation should be done as soon as possible [22]. In addition, switching to spontaneous ventilation is essential for accurate assessment of respiratory muscle function. Maximum inspiratory pressure (MIP) is a simple measure of all the inspiratory muscles together. This measurement is often available on ventilators: a value below $30 \mathrm{cmH} 2 \mathrm{O}$ is defined as indicative of respiratory muscle weakness and predictive of difficult weaning from mechanical ventilation [23]. MIP measurements can be repeated daily to monitor progress and are considered valid in patients who respond to simple orders. The assessment of voluntary muscle strength (MRC-SS and MIP) is limited to patients who are both awake and cooperative. in non-cooperative patients, ultrasound is a reliable, sensitive, and valid tool to assess diaphragm $[24,25,26]$ and quadriceps strength [27].

Once sedation has been stopped or after weaning from mechanical ventilation, it is important to assess the patient's functional capacity in order to guide further physical rehabilitation. Scales such as the 5-meter walk test or the 5 times sit-to-stand test may be useful [28, 29].

\section{Could airways clearance techniques help the patients?}

In patients on mechanical ventilation, chest physiotherapy does not lead to further improvements in ventilatory function or gas exchange [30], therefore it is of no interest for patients with COVID-19.

\section{How to preserve functional capacity in patients in ICU?}

Neuromuscular Electrical Stimulation (NMES) is a non-invasive and easy to perform technique that does not require prolonged exposure of the physiotherapist to the patient. Several systematic reviews have suggested that NMES preserves muscle strength, mass and architecture [31, 32, 33]. However, the results of the studies included in those systematic reviews are not always clinically relevant and need to be considered with caution[34].

Early rehabilitation including passive mobilization exercises do not decrease the duration of hospitalization and mechanical ventilation in 
patients with acute respiratory failure [35]. Interestingly, Griffiths et al. showed a modest benefit of passive mobilization on muscle trophicity when it was performed for three hours at a time, three times a day [36], which is not feasible in clinical practice. Thus, in view of the absence of benefits described in the literature, passive range of motion exercises are not a priority intervention for patients on mechanical ventilation and should not be performed [37].

A recent study showed that a comprehensive rehabilitation program including the addition of an in-bed cycle ergometer with quadriceps electrostimulation did not improve muscle strength more than standard rehabilitation alone with patients exercising out of bed [38]. These results suggest that when patients can perform exercise out of bed, the use of an inbed cycle-ergometer does not provide any additional benefit. However, inbed cycle-ergometry could be considered for patients who cannot perform exercise out of bed because it may provide some benefit above no exercise. Functional electrical stimulation cycling could also be considered, because it provides more intense exercise than in-bed cycle-ergometry alone [39].

In view of the lack of effectiveness of in-bed techniques, it is important to get the patient out of bed as soon as possible. A comprehensive physiotherapy program with out-of-bed exercises can increase muscle strength and recovery of functional capacity and reduce ICU delirium [40]. Active exercises can be initiated once sedation has been stopped and when the patient can respond to simple orders. Patients who tolerate this can be actively positioned using different types of supportive devices (stretcher chairs, standing frames etc.). Passive verticalization on a tilt table does not affect muscle strength [41] and active verticalization should mostly be considered. Several studies have shown no benefits of intensive early rehabilitation over standard rehabilitation including exercise out of bed [42, 43]. Therefore, in the context of COVID-19, intensive early rehabilitation should not be carried out.

The reduction in gas exchange associated with lung infection can cause severe hypoxemia during rehabilitation sessions. In patients with unstable SpO2 levels it is advisable to adjust their oxygen intake in order to maintain an $\mathrm{SpO} 2$ of $94 \%$ during the training sessions [44]. In order to limit desaturation, in the cases where oxygen intake cannot be adjusted, exercise intensity can also be decreased [45].

Finally, considering the risk of transmission and the evidences, inspiratory muscles training using valve does not seem appropriate [46, 47]. In case of inspiratory muscle weakness, we recommend establishing a protocol in order to gradually decrease the levels of ventilatory support and monitor the evolution of inspiratory muscle strength.

\section{Physiotherapy for non-ventilated patients}

In view of the exceptional nature of the current health situation, a dedicated physiotherapist should be in charge of patients with COVID-19 whenever possible. If this is not possible, isolation procedures should be followed and physiotherapists in contact with patients with COVID-19 should not also treat vulnerable, non-infected patients. A meticulous organization of the care schedule and staff must be put in place to minimize the risk of transmission. Finally, the potential benefits of any intervention must constantly be weighed against any possible risk of cross-contamination. In patients who are less severely affected physiotherapists can limit their interventions to the provision of advice and instructions regarding exercises that the patient can perform independently (eg. standing up regularly, walking in the room every hour, use of elastic bands for strengthening; depending on the patient's tolerance and ability). Patients should be encouraged to sit out of bed as much as possible and to carry out their own activities of daily living [44].

\section{Are airway clearance techniques useful?}

Two published cohort studies reported that between 20 and 30\% of patients with COVID-19 produce sputum $[5,48]$. Nevertheless, it is note-

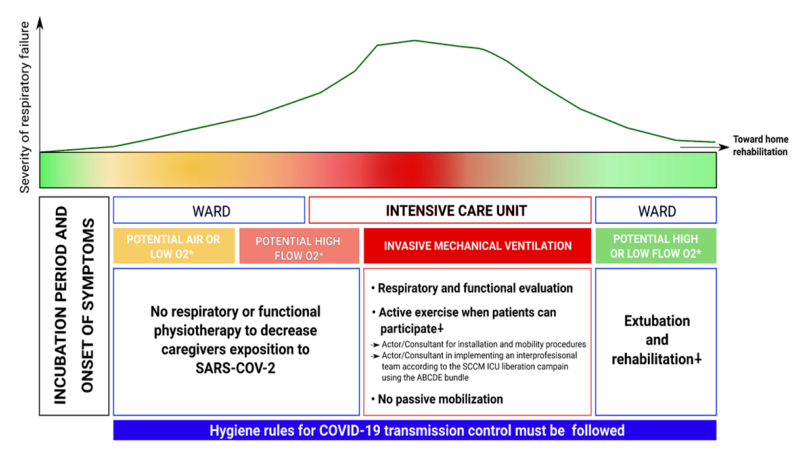

Figure 1 Clinical course and outcomes in critical care patients and management strategies for physiotherapists. Based on data from Wang et al.,Yang et al., Wu et al and Bouadma et al. [1, 4, 11, 21]. aerosolgenerating procedure; non aerosol-generating procedure". ABCDE: Awakening and Breathing Coordination, Delirium, and Early exercise/mobility; NEMS: Neuromuscular Electrical Stimulation; O2: oxygen

worthy to mention that if the patient has an effective cough and does not retain secretions, the literature does not support the use of airways clearance techniques [49]: chest physiotherapy is not recommended as routine treatment for pneumonia in adults [50]. In addition, airway clearance techniques can tremendously increase the risk of contamination because of droplet dispersion in the environment. This is also the case for instrumental techniques (incentive spirometry, positive expiratory pressure masks, etc.) that can cause aerosolization and are therefore not advised [51]. However, chest physiotherapy may be indicated for patients with underlying secretion clearing issues (such as bronchiectasis or cystic fibrosis) [52].

\section{Physiotherapy following discharge from intensive care}

Evidence regarding the potential long-term consequences of viral infections causing acute severe respiratory diseases is scarce. Data from the influenza A epidemics showed that survivors had substantial alterations in their lung function up to 2 years after being discharged from hospital $[53,54]$. In addition to impaired lung function, exercise capacity is markedly reduced in survivors $[55,56]$. In the COVID-19 epidemic, a large number of patients admitted to the ICU develop ARDS [4]. This condition is strongly correlated with a decrease in long-term functional capacity [57], in particular muscle strength and walking distance [58] Ong et al. showed that $41 \%$ of subjects had a loss of maximum aerobic capacity compared to normal values 3 months after hospital discharge [55]. Exercise capacity is an important determinant of quality of life. Data from 110 SARS survivors showed they had a significantly reduced quality of life compared to the general population [56]. Finally, the long-term consequences of ARDS on mental health should not be overlooked. Depression and anxiety are also very common in survivors of ARDS, with a prevalence above $26 \%$ and $28 \%$ respectively [58].

\section{How to continue physiotherapy after discharge?}

Patients who have been ventilated for more than seven days and who have a significant loss of functional capacity are likely to respond the best to an inpatient or day-care rehabilitation program. This group of patients is at higher risk of hospital readmission should be closely monitored [59]. Those patients, and their rehabilitation needs, can be identified by physiotherapists through simple functional tests such as the sit to stand test ( 30 seconds or one minute), the time up and go test (TUG) or the physical function in ICU test (PFIT test). In order to prevent cross-transmission of the virus, it is not useful to provide 
supervised rehabilitation to patients who are independent, have no muscle weakness or who have a low risk of deconditioning [60]. In this case telerehabilitation could be discussed.

For patients who do not have access to a rehabilitation center, treatment at home or in an out-patient physiotherapy practice should be considered. The provision of a booklet containing a six-week program of home exercises has been shown to optimize functional recovery [61]. The exercises should be simple with minimal need for equipment (e.g. standing up from a chair, climbing stairs, walking 30 minutes a day, strengthening exercises using bottles of water etc.). The intensity of physical activity should be low ( 3 on the modified Borg scale) for the first 6 to 8 weeks after discharge from hospital [60]. The proportion of patients with COVID-19 and severe residual hypoxemia during exercise is currently unknown. Physiotherapists should monitor SpO2 during exercise to measure the severity of hypoxemia. If the patient uses oxygen, titration is recommended in order to maintain $90 \% \mathrm{SpO} 2$ [45]. For patients who are not on oxygen, supplementation should be discussed with their physician and the intensity of the exercise should be reduced.

To increase patient adherence to a home exercise program, the patient can be instructed to keep a log-book of daily activities and to identify any barriers that prevent him/her from carrying out any activities. Simple tools such as a pedometer can be useful to motivate patients. A weekly follow-up telephone call or a home visit may be necessary to supervise the exercise program, answer the patient's questions and provide motivational coaching [62]. Tele-rehabilitation can also be useful [63] and could be particularly appropriate in the context of the COVID-19 epidemic.

\section{Conclusion}

The COVID-19 pandemic is one of the largest that the world has faced in the last fifty years, resulting in a high number of hospitalizations and saturating intensive care units. In this context, physiotherapists have an important role to play in helping patients return to their highest level of function, in the ICU or following discharge from the hospital. Finally, in view of the very high proportion of patients who are likely to have persistent loss of functional capacity following discharge, clinical research should aim to rapidly evaluate new management strategies and tools such as tele-rehabilitation and unsupervised rehabilitation in order to help patients to regain physical and cognitive function.

\section{References}

[1] Zunyou Wu and Jennifer M. McGoogan. Characteristics of and Important Lessons From the Coronavirus Disease 2019 (COVID-19) Outbreak in China: Summary of a Report of 72314 Cases From the Chinese Center for Disease Control and Prevention. JAMA, 323 (13):1239, April 2020. ISSN 0098-7484. doi: 10.1001/jama.2020. 2648. URL https://jamanetwork.com/journals/jama/fullarticle/ 2762130

[2] David Baud, Xiaolong Qi, Karin Nielsen-Saines, Didier Musso, Léo Pomar, and Guillaume Favre. Real estimates of mortality following COVID-19 infection. The Lancet Infectious Diseases, 20(7):773, July 2020. ISSN 14733099. doi: 10.1016/ S1473-3099(20)30195-X. URL https://linkinghub.elsevier.com/ retrieve/pii/S147330992030195X.

[3] Xiaobo Yang, Yuan Yu, Jiqian Xu, Huaqing Shu, Jia'an Xia, Hong Liu, Yongran Wu, Lu Zhang, Zhui Yu, Minghao Fang, Ting Yu, Yaxin Wang, Shangwen Pan, Xiaojing Zou, Shiying Yuan, and You Shang. Clinical course and outcomes of critically ill patients with SARS-CoV-2 pneumonia in Wuhan, China: a singlecentered, retrospective, observational study. The Lancet Respiratory Medicine, 8(5):475-481, May 2020. ISSN 22132600. doi:
10.1016/S2213-2600(20)30079-5. URL https://linkinghub.elsevier. com/retrieve/pii/S2213260020300795.

[4] Dawei Wang, Bo Hu, Chang Hu, Fangfang Zhu, Xing Liu, Jing Zhang, Binbin Wang, Hui Xiang, Zhenshun Cheng, Yong Xiong, Yan Zhao, Yirong Li, Xinghuan Wang, and Zhiyong Peng. Clinical Characteristics of 138 Hospitalized Patients With 2019 Novel Coronavirus-Infected Pneumonia in Wuhan, China. JAMA, 323(11):1061, March 2020. ISSN 0098-7484. doi: 10.1001/jama.2020.1585. URL https://jamanetwork.com/journals/jama/fullarticle/2761044.

[5] Fei Zhou, Ting Yu, Ronghui Du, Guohui Fan, Ying Liu, Zhibo Liu, Jie Xiang, Yeming Wang, Bin Song, Xiaoying Gu, Lulu Guan, Yuan Wei, Hui Li, Xudong Wu, Jiuyang Xu, Shengjin Tu, Yi Zhang, Hua Chen, and Bin Cao. Clinical course and risk factors for mortality of adult inpatients with COVID-19 in Wuhan, China: a retrospective cohort study. The Lancet, 395(10229):1054-1062, March 2020. ISSN 01406736. doi: 10.1016/S0140-6736(20)30566-3. URL https: //linkinghub.elsevier.com/retrieve/pii/S0140673620305663.

[6] Qiurong Ruan, Kun Yang, Wenxia Wang, Lingyu Jiang, and Jianxin Song. Clinical predictors of mortality due to COVID-19 based on an analysis of data of 150 patients from Wuhan, China. Intensive Care Medicine, 46(5):846-848, May 2020. ISSN 0342-4642, 1432-1238. doi: 10.1007/s00134-020-05991-x. URL http://link.springer.com/ 10.1007/s00134-020-05991-x.

[7] Qun Li, Xuhua Guan, Peng Wu, Xiaoye Wang, Lei Zhou, Yeqing Tong, Ruiqi Ren, Kathy S.M. Leung, Eric H.Y. Lau, Jessica Y. Wong, Xuesen Xing, Nijuan Xiang, Yang Wu, Chao Li, Qi Chen, Dan Li, Tian Liu, Jing Zhao, Man Liu, Wenxiao Tu, Chuding Chen, Lianmei Jin, Rui Yang, Qi Wang, Suhua Zhou, Rui Wang, Hui Liu, Yinbo Luo, Yuan Liu, Ge Shao, Huan Li, Zhongfa Tao, Yang Yang, Zhiqiang Deng, Boxi Liu, Zhitao Ma, Yanping Zhang, Guoqing Shi, Tommy T.Y. Lam, Joseph T. Wu, George F. Gao, Benjamin J. Cowling, Bo Yang, Gabriel M. Leung, and Zijian Feng. Early Transmission Dynamics in Wuhan, China, of Novel Coronavirus-Infected Pneumonia. New England Journal of Medicine, 382(13):1199-1207, March 2020. ISSN 0028-4793, 1533-4406. doi: 10.1056/NEJMoa2001316. URL http://www.nejm.org/doi/10.1056/NEJMoa2001316.

[8] Lila Bouadma, Francois-Xavier Lescure, Jean-Christophe Lucet, Yazdan Yazdanpanah, and Jean-Francois Timsit. Severe SARS-CoV-2 infections: practical considerations and management strategy for intensivists. Intensive Care Medicine, 46(4):579-582, April 2020. ISSN 0342-4642, 1432-1238. doi: 10.1007/s00134-020-05967-x. URL http://link.springer.com/10.1007/s00134-020-05967-x.

[9] Youlin Long, Tengyue Hu, Liqin Liu, Rui Chen, Qiong Guo, Liu Yang, Yifan Cheng, Jin Huang, and Liang Du. Effectiveness of N95 respirators versus surgical masks against influenza: A systematic review and meta-analysis. Journal of Evidence-Based Medicine, 13(2): 93-101, May 2020. ISSN 1756-5383, 1756-5391. doi: 10.1111/jebm. 12381. URL https://onlinelibrary.wiley.com/doi/abs/10.1111/jebm. 12381.

[10] Xu Wang, Xiaoxi Zhang, and Jiangjiang He. Challenges to the system of reserve medical supplies for public health emergencies: reflections on the outbreak of the severe acute respiratory syndrome coronavirus 2 (sars-cov-2) epidemic in china. Bioscience trends, 14(1):3-8, 2020.

[11] Waleed Alhazzani, Morten Hylander Møller, Yaseen M. Arabi, Mark Loeb, Michelle Ng Gong, Eddy Fan, Simon Oczkowski, Mitchell M. Levy, Lennie Derde, Amy Dzierba, Bin Du, Michael Aboodi, Hannah Wunsch, Maurizio Cecconi, Younsuck Koh, Daniel S. Chertow, 
Kathryn Maitland, Fayez Alshamsi, Emilie Belley-Cote, Massimiliano Greco, Matthew Laundy, Jill S. Morgan, Jozef Kesecioglu, Allison McGeer, Leonard Mermel, Manoj J. Mammen, Paul E. Alexander, Amy Arrington, John E. Centofanti, Giuseppe Citerio, Bandar Baw, Ziad A. Memish, Naomi Hammond, Frederick G. Hayden, Laura Evans, and Andrew Rhodes. Surviving Sepsis Campaign: Guidelines on the Management of Critically Ill Adults with Coronavirus Disease 2019 (COVID-19). Critical Care Medicine, 48(6):e440-e469, June 2020. ISSN 0090-3493. doi: 10.1097/CCM.0000000000004363. URL https://journals.Iww.com/ 10.1097/CCM.0000000000004363.

[12] DavidG. Ashbaugh, D. Boyd Bigelow, ThomasL. Petty, and BernardE. Levine. ACUTE RESPIRATORY DISTRESS IN ADULTS. The Lancet, 290(7511):319-323, August 1967. ISSN 01406736. doi: 10.1016/S0140-6736(67)90168-7. URL https://linkinghub.elsevier. com/retrieve/pii/S0140673667901687.

[13] Eddy Fan, Lorenzo Del Sorbo, Ewan C. Goligher, Carol L. Hodgson, Laveena Munshi, Allan J. Walkey, Neill K. J. Adhikari, Marcelo B. P. Amato, Richard Branson, Roy G. Brower, Niall D. Ferguson, Ognjen Gajic, Luciano Gattinoni, Dean Hess, Jordi Mancebo, Maureen O. Meade, Daniel F. McAuley, Antonio Pesenti, V. Marco Ranieri, Gordon D. Rubenfeld, Eileen Rubin, Maureen Seckel, Arthur S. Slutsky, Daniel Talmor, B. Taylor Thompson, Hannah Wunsch, Elizabeth Uleryk, Jan Brozek, and Laurent J. Brochard. An Official American Thoracic Society/European Society of Intensive Care Medicine/Society of Critical Care Medicine Clinical Practice Guideline: Mechanical Ventilation in Adult Patients with Acute Respiratory Distress Syndrome. American Journal of Respiratory and Critical Care Medicine, 195(9):1253-1263, May 2017. ISSN 1073-449X, 1535-4970. doi: 10.1164/rccm.201703-0548ST. URL http://www.atsjournals.org/doi/10.1164/rccm.201703-0548ST.

[14] Richard D. Zorowitz. ICU-Acquired Weakness. Chest, 150(4): 966-971, October 2016. ISSN 00123692. doi: 10.1016/j.chest. 2016.06.006. URL https://linkinghub.elsevier.com/retrieve/pii/ S0012369216502517.

[15] Margaret S. Herridge, Catherine M. Tansey, Andrea Matté, George Tomlinson, Natalia Diaz-Granados, Andrew Cooper, Cameron B. Guest, C. David Mazer, Sangeeta Mehta, Thomas E. Stewart, Paul Kudlow, Deborah Cook, Arthur S. Slutsky, and Angela M. Cheung. Functional Disability 5 Years after Acute Respiratory Distress Syndrome. New England Journal of Medicine, 364(14):1293-1304, April 2011. ISSN 0028-4793, 1533-4406. doi: 10.1056/NEJMoa1011802. URL http://www.nejm.org/doi/abs/10.1056/NEJMoa1011802.

[16] Jane Batt, Sunita Mathur, and Hans D. Katzberg. Mechanism of ICUacquired weakness: muscle contractility in critical illness. Intensive Care Medicine, 43(4):584-586, April 2017. ISSN 0342-4642, 14321238. doi: 10.1007/s00134-017-4730-3. URL http://link.springer. $\mathrm{com} / 10.1007 / \mathrm{s} 00134-017-4730-3$.

[17] Jane Batt, Claudia C. dos Santos, Jill I. Cameron, and Margaret S. Herridge. Intensive Care Unit-acquired Weakness: Clinical Phenotypes and Molecular Mechanisms. American Journal of Respiratory and Critical Care Medicine, 187(3):238-246, February 2013. ISSN 1073449X, 1535-4970. doi: 10.1164/rccm.201205-0954SO. URL http:// www.atsjournals.org/doi/abs/10.1164/rccm.201205-0954SO.

[18] Ilse Vanhorebeek, Nicola Latronico, and Greet Van den Berghe. Icuacquired weakness. Intensive care medicine, 46(4):637-653, 2020.
[19] Nathalie Van Aerde, Philippe Meersseman, Yves Debaveye, Alexander Wilmer, Jan Gunst, Michael P. Casaer, Frans Bruyninckx, Pieter J. Wouters, Rik Gosselink, Greet Van den Berghe, and Greet Hermans. Five-year impact of ICU-acquired neuromuscular complications: a prospective, observational study. Intensive Care Medicine, 46(6):1184-1193, June 2020. ISSN 0342-4642, 1432-1238. doi: 10.1007/s00134-020-05927-5. URL http://link.springer.com/10. 1007/s00134-020-05927-5.

[20] James M Smith, Alan C Lee, Hallie Zeleznik, Jacqueline P Coffey Scott, Arooj Fatima, Dale M Needham, and Patricia J Ohtake. Home and Community-Based Physical Therapist Management of Adults With Post-Intensive Care Syndrome. Physical Therapy, 100(7):1062-1073, July 2020. ISSN 0031-9023, 1538-6724. doi: 10.1093/ptj/pzaa059. URL https://academic.oup.com/ptj/article/ 100/7/1062/5818366.

[21] Clément Medrinal, Yann Combret, Roger Hilfiker, Guillaume Prieur, Nadine Aroichane, Francis-Edouard Gravier, Tristan Bonnevie, Olivier Contal, and Bouchra Lamia. ICU outcomes can be predicted by noninvasive muscle evaluation: a meta-analysis. European Respiratory Journal, 56(4):1902482, October 2020. ISSN 09031936, 1399-3003. doi: 10.1183/13993003.02482-2019. URL http://erj. ersjournals.com/lookup/doi/10.1183/13993003.02482-2019.

[22] Tom Schepens and Jose Dianti. Diaphragm protection: what should we target? Current Opinion in Critical Care, 26(1):3540, February 2020. ISSN 1070-5295. doi: 10.1097/MCC. 0000000000000683. URL http://journals.Iww.com/10.1097/MCC. 0000000000000683.

[23] Clément Medrinal, Guillaume Prieur, Éric Frenoy, Aurora Robledo Quesada, Antoine Poncet, Tristan Bonnevie, Francis-Edouard Gravier, Bouchra Lamia, and Olivier Contal. Respiratory weakness after mechanical ventilation is associated with one-year mortality a prospective study. Critical Care, 20(1):231, December 2016. ISSN 1364-8535. doi: 10.1186/s13054-016-1418-y. URL http://ccforum. biomedcentral.com/articles/10.1186/s13054-016-1418-y.

[24] Bruno-Pierre Dubé, Martin Dres, Julien Mayaux, Suela Demiri, Thomas Similowski, and Alexandre Demoule. Ultrasound evaluation of diaphragm function in mechanically ventilated patients: comparison to phrenic stimulation and prognostic implications. Thorax, 72(9):811-818, September 2017. ISSN 0040-6376, 1468-3296. doi: 10.1136/thoraxjnl-2016-209459. URL https://thorax.bmj.com/ lookup/doi/10.1136/thoraxjnl-2016-209459.

[25] Boris Jung, Pierre Henri Moury, Martin Mahul, Audrey de Jong, Fabrice Galia, Albert Prades, Pierre Albaladejo, Gerald Chanques, Nicolas Molinari, and Samir Jaber. Diaphragmatic dysfunction in patients with ICU-acquired weakness and its impact on extubation failure. Intensive Care Medicine, 42(5):853-861, May 2016. ISSN 0342-4642, 1432-1238. doi: 10.1007/s00134-015-4125-2. URL http: //link.springer.com/10.1007/s00134-015-4125-2.

[26] Aymeric Le Neindre, Silvia Mongodi, François Philippart, and Bélaïd Bouhemad. Thoracic ultrasound: Potential new tool for physiotherapists in respiratory management. A narrative review. Journal of Critical Care, 31(1):101-109, February 2016. ISSN 08839441. doi: 10.1016/j.jcrc.2015.10.014. URL https://linkinghub.elsevier.com/ retrieve/pii/S0883944115005444.

[27] Paolo Formenti, Michele Umbrello, Silvia Coppola, Sara Froio, and Davide Chiumello. Clinical review: peripheral muscular ultrasound in the ICU. Annals of Intensive Care, 9(1):57, December 2019. ISSN 2110-5820. doi: 10.1186/s13613-019-0531-x. 
URL https://annalsofintensivecare.springeropen.com/articles/ 10.1186/s13613-019-0531-x.

[28] Amy Nordon-Craft, Marc Moss, Dianna Quan, and Margaret Schenkman. Intensive Care Unit-Acquired Weakness: Implications for Physical Therapist Management. Physical Therapy, 92 (12):1494-1506, December 2012. ISSN 0031-9023, 1538-6724. doi: 10.2522/ptj.20110117. URL https://academic.oup.com/ptj/article/ 92/12/1494/2735225.

[29] Stephen M. Haley, Pengsheng Ni, Jin-Shei Lai, Feng Tian, Wendy J. Coster, Alan M. Jette, Donald Straub, and David Cella. Linking the Activity Measure for Post Acute Care and the Quality of Life Outcomes in Neurological Disorders. Archives of Physical Medicine and Rehabilitation, 92(10):S37-S43, October 2011. ISSN 00039993. doi: 10.1016/j.apmr.2011.01.026. URL https://linkinghub.elsevier. com/retrieve/pii/S0003999311006824.

[30] Elaine Cristina Gonçalves, Hugo C. D. Souza, Joana Tambascio, Marcelo Barros Almeida, Anibal Basile Filho, and Ada Clarice Gastaldi. Effects of chest compression on secretion removal, lung mechanics, and gas exchange in mechanically ventilated patients: a crossover, randomized study. Intensive Care Medicine, 42 (2):295-296, February 2016. ISSN 0342-4642, 1432-1238. doi: 10. 1007/s00134-015-4117-2. URL http://link.springer.com/10.1007/ s00134-015-4117-2.

[31] Dearbhla Burke, Emma Gorman, Diarmaid Stokes, and Olive Lennon. An evaluation of neuromuscular electrical stimulation in critical care using the icf framework: a systematic review and meta-analysis. The clinical respiratory journal, 10(4):407-420, 2016.

[32] B. Wageck, G.S. Nunes, F.L. Silva, M.C.P. Damasceno, and M. de Noronha. Application and effects of neuromuscular electrical stimulation in critically ill patients: Systematic review. Medicina Intensiva, 38(7):444-454, October 2014. ISSN 02105691. doi: 10.1016/j.medin.2013.12.003. URL https://linkinghub.elsevier.com/ retrieve/pii/S0210569114000084.

[33] Selina M. Parry, Sue Berney, Catherine L. Granger, Renè Koopman, Doa El-Ansary, and Linda Denehy. Electrical Muscle Stimulation in the Intensive Care Setting: A Systematic Review*. Critical Care Medicine, 41(10):2406-2418, October 2013. ISSN 0090-3493. doi: 10.1097/CCM.0b013e3182923642. URL http://journals.Iww.com/ 00003246-201310000-00017.

[34] Y. Zayed, B. Kheiri, M. Barbarawi, A. Chahine, L. Rashdan, S. Chintalapati, G. Bachuwa, and I. Al-Sanouri. Effects of neuromuscular electrical stimulation in critically ill patients: A systematic review and meta-analysis of randomised controlled trials. Australian Critical Care, 33(2):203-210, March 2020. ISSN 10367314. doi: 10.1016/j.aucc.2019.04.003. URL https://linkinghub.elsevier.com/ retrieve/pii/S1036731419300013.

[35] Peter E. Morris, Michael J. Berry, D. Clark Files, J. Clifton Thompson, Jordan Hauser, Lori Flores, Sanjay Dhar, Elizabeth Chmelo, James Lovato, L. Douglas Case, Rita N. Bakhru, Aarti Sarwal, Selina M. Parry, Pamela Campbell, Arthur Mote, Chris Winkelman, Robert D. Hite, Barbara Nicklas, Arjun Chatterjee, and Michael P. Young. Standardized Rehabilitation and Hospital Length of Stay Among Patients With Acute Respiratory Failure: A Randomized Clinical Trial. JAMA, 315(24):2694, June 2016. ISSN 0098-7484. doi: 10.1001/ jama.2016.7201. URL http://jama.jamanetwork.com/article.aspx? doi=10.1001/jama.2016.7201.
[36] Richard D Griffiths, TE Palmer, Timothy Helliwell, Peter Maclennan, and Robin R MacMillan. Effect of passive stretching on the wasting of muscle in the critically ill. Nutrition (Burbank, Los Angeles County, Calif.), 11(5):428-432, 1995.

[37] Clément Medrinal, Yann Combret, Guillaume Prieur, Aurora Robledo Quesada, Tristan Bonnevie, Francis Edouard Gravier, Elise Dupuis Lozeron, Eric Frenoy, Olivier Contal, and Bouchra Lamia. Comparison of exercise intensity during four early rehabilitation techniques in sedated and ventilated patients in ICU: a randomised cross-over trial. Critical Care, 22(1):110, December 2018. ISSN 1364-8535. doi: 10.1186/s13054-018-2030-0. URL https://ccforum. biomedcentral.com/articles/10.1186/s13054-018-2030-0.

[38] Guillaume Fossat, Florian Baudin, Léa Courtes, Sabrine Bobet, Arnaud Dupont, Anne Bretagnol, Dalila Benzekri-Lefèvre, Toufik Kamel, Grégoire Muller, Nicolas Bercault, François Barbier, Isabelle Runge, Mai-Anh Nay, Marie Skarzynski, Armelle Mathonnet, and Thierry Boulain. Effect of In-Bed Leg Cycling and Electrical Stimulation of the Quadriceps on Global Muscle Strength in Critically Ill Adults: A Randomized Clinical Trial. JAMA, 320(4):368, July 2018. ISSN 0098-7484. doi: 10.1001/jama.2018.9592. URL http://jama. jamanetwork.com/article.aspx?doi=10.1001/jama.2018.9592.

[39] Chris Burtin, Beatrix Clerckx, Christophe Robbeets, Patrick Ferdinande, Daniel Langer, Thierry Troosters, Greet Hermans, Marc Decramer, and Rik Gosselink. Early exercise in critically ill patients enhances short-term functional recovery*:. Critical Care Medicine, 37(9):2499-2505, September 2009. ISSN 0090-3493. doi: 10.1097/CCM.0b013e3181a38937. URL http://journals.Iww.com/ 00003246-200909000-00001.

[40] William D Schweickert, Mark C Pohlman, Anne S Pohlman, Celerina Nigos, Amy J Pawlik, Cheryl L Esbrook, Linda Spears, Megan Miller, Mietka Franczyk, Deanna Deprizio, Gregory A Schmidt, Amy Bowman, Rhonda Barr, Kathryn E McCallister, Jesse B Hall, and John P Kress. Early physical and occupational therapy in mechanically ventilated, critically ill patients: a randomised controlled trial. The Lancet, 373(9678):1874-1882, May 2009. ISSN 01406736. doi: 10.1016/S0140-6736(09)60658-9. URL https: //linkinghub.elsevier.com/retrieve/pii/S0140673609606589.

[41] Céline Sarfati, Alex Moore, Catherine Pilorge, Priscilla Amaru, Paula Mendialdua, Emilie Rodet, François Stéphan, and Saïda Rezaiguia-Delclaux. Efficacy of early passive tilting in minimizing ICU-acquired weakness: A randomized controlled trial. Journal of Critical Care, 46:37-43, August 2018. ISSN 08839441. doi: 10.1016/j.jcrc.2018.03.031. URL https://linkinghub.elsevier.com/ retrieve/pii/S0883944118301084.

[42] Marc Moss, Amy Nordon-Craft, Dan Malone, David Van Pelt, Stephen K. Frankel, Mary Laird Warner, Wendy Kriekels, Monica McNulty, Diane L. Fairclough, and Margaret Schenkman. A Randomized Trial of an Intensive Physical Therapy Program for Patients with Acute Respiratory Failure. American Journal of Respiratory and Critical Care Medicine, 193(10):11011110, May 2016. ISSN 1073-449X, 1535-4970. doi: 10.1164/ rccm.201505-1039OC. URL http://static.thoracic.org/podcast/ AJRCCM-interviews/rccm-201505-10390C.mp3.

[43] Stephen E Wright, Kirsty Thomas, Gillian Watson, Catherine Baker, Andrew Bryant, Thomas J Chadwick, Jing Shen, Ruth Wood, Jennifer Wilkinson, Leigh Mansfield, Victoria Stafford, Clare Wade, Julie Furneval, Andrea Henderson, Keith Hugill, Philip Howard, Alistair Roy, Stephen Bonner, and Simon Baudouin. Intensive 
versus standard physical rehabilitation therapy in the critically ill (EPICC): a multicentre, parallel-group, randomised controlled trial. Thorax, 73(3):213-221, March 2018. ISSN 0040-6376, 1468-3296. doi: 10.1136/thoraxjnl-2016-209858. URL https://thorax.bmj.com/ lookup/doi/10.1136/thoraxjnl-2016-209858.

[44] Peter Thomas, Claire Baldwin, Bernie Bissett, Ianthe Boden, Rik Gosselink, Catherine L Granger, Carol Hodgson, Alice YM Jones, Michelle E Kho, Rachael Moses, George Ntoumenopoulos, Selina M Parry, Shane Patman, and Lisa van der Lee. Physiotherapy management for COVID-19 in the acute hospital setting: clinical practice recommendations. Journal of Physiotherapy, 66(2):73-82, April 2020. ISSN 18369553. doi: 10.1016/j.jphys.2020.03.011. URL https: //linkinghub.elsevier.com/retrieve/pii/S183695532030028X.

[45] Ellen Hillegass, Ann Fick, Amy Pawlik, Rebecca Crouch, Christiane Perme, Rohini Chandrashekar, Susan Butler McNamara, and Lawrence P Cahalin. Supplemental oxygen utilization during physical therapy interventions. Cardiopulmonary Physical Therapy Journal, 25(2):38-49, 2014.

[46] Stefannie Vorona, Umberto Sabatini, Sulaiman Al-Maqbali, Michele Bertoni, Martin Dres, Bernie Bissett, Frank Van Haren, A. Daniel Martin, Cristian Urrea, Debbie Brace, Matteo Parotto, Margaret S. Herridge, Neill K. J. Adhikari, Eddy Fan, Luana T. Melo, W. Darlene Reid, Laurent J. Brochard, Niall D. Ferguson, and Ewan C. Goligher. Inspiratory Muscle Rehabilitation in Critically Ill Adults. A Systematic Review and Meta-Analysis. Annals of the American Thoracic Society, 15(6):735-744, June 2018. ISSN 2329-6933, 2325-6621. doi: 10.1513/AnnalsATS.201712-961OC. URL https://www.atsjournals. org/doi/10.1513/AnnalsATS.201712-9610C.

[47] Mark Elkins and Ruth Dentice. Inspiratory muscle training facilitates weaning from mechanical ventilation among patients in the intensive care unit: a systematic review. Journal of Physiotherapy, 61(3):125-134, July 2015. ISSN 18369553. doi: 10.1016/j.jphys. 2015.05.016. URL https://linkinghub.elsevier.com/retrieve/pii/ S1836955315000557.

[48] Wei-jie Guan, Zheng-yi Ni, Yu Hu, Wen-hua Liang, Chun-quan Ou, Jian-xing He, Lei Liu, Hong Shan, Chun-liang Lei, David S.C. Hui, Bin Du, Lan-juan Li, Guang Zeng, Kwok-Yung Yuen, Ru-chong Chen, Chun-li Tang, Tao Wang, Ping-yan Chen, Jie Xiang, Shi-yue Li, Jin-lin Wang, Zi-jing Liang, Yi-xiang Peng, Li Wei, Yong Liu, Ya-hua Hu, Peng Peng, Jian-ming Wang, Ji-yang Liu, Zhong Chen, Gang Li, Zhi-jian Zheng, Shao-qin Qiu, Jie Luo, Chang-jiang Ye, Shao-yong Zhu, and Nan-shan Zhong. Clinical Characteristics of Coronavirus Disease 2019 in China. New England Journal of Medicine, 382(18):1708-1720, April 2020. ISSN 0028-4793, 1533-4406. doi: 10.1056/NEJMoa2002032. URL http://www.nejm.org/doi/10.1056/ NEJMoa2002032.

[49] S. L. Strickland, B. K. Rubin, G. S. Drescher, C. F. Haas, C. A. O'Malley, T. A. Volsko, R. D. Branson, and D. R. Hess. AARC Clinical Practice Guideline: Effectiveness of Nonpharmacologic Airway Clearance Therapies in Hospitalized Patients. Respiratory Care, 58(12):2187-2193, December 2013. ISSN 0020-1324, 1943-3654. doi: 10.4187/respcare.02925. URL http://rc.rcjournal.com/cgi/doi/10. 4187/respcare.02925.

[50] Ming Yang, Yuping Yan, Xiangli Yin, Bin Y Wang, Taixiang Wu, Guan J Liu, and Bi Rong Dong. Chest physiotherapy for pneumonia in adults. Cochrane Database of Systematic Reviews, February 2013. ISSN 14651858. doi: 10.1002/14651858.CD006338.pub3. URL http: //doi.wiley.com/10.1002/14651858.CD006338.pub3.
[51] Ak Simonds, A Hanak, M Chatwin, Mj Morrell, A Hall, Kh Parker, Jh Siggers, and Rj Dickinson. Evaluation of droplet dispersion during non-invasive ventilation, oxygen therapy, nebuliser treatment and chest physiotherapy in clinical practice: implications for management of pandemic influenza and other airborne infections. Health Technology Assessment, 14(46), October 2010. ISSN 1366-5278, 2046-4924. doi: 10.3310/hta14460-02. URL https: //www.journalslibrary.nihr.ac.uk/hta/hta14460-02/.

[52] Jaafer Saadi Imam and Alexander G. Duarte. Non-CF bronchiectasis: Orphan disease no longer. Respiratory Medicine, 166:105940, May 2020. ISSN 09546111. doi: 10.1016/j.rmed.2020.105940. URL https: //linkinghub.elsevier.com/retrieve/pii/S0954611120300809.

[53] Jiajia Chen, Jie Wu, Shaorui Hao, Meifang Yang, Xiaoqing Lu, Xiaoxiao Chen, and Lanjuan Li. Long term outcomes in survivors of epidemic Influenza A (H7N9) virus infection. Scientific Reports, 7(1):17275, December 2017. ISSN 2045-2322. doi: 10. 1038/s41598-017-17497-6. URL http://www.nature.com/articles/ s41598-017-17497-6.

[54] Wei Liu, Liping Peng, Hongmei Liu, and Shucheng Hua. Pulmonary Function and Clinical Manifestations of Patients Infected with Mild Influenza A Virus Subtype H1N1: A One-Year Follow-Up. PLOS ONE, 10(7):e0133698, July 2015. ISSN 1932-6203. doi: 10.1371/ journal.pone.0133698. URL https://dx.plos.org/10.1371/journal. pone.0133698.

[55] K-C. Ong. Pulmonary function and exercise capacity in survivors of severe acute respiratory syndrome. European Respiratory Journal, 24(3):436-442, September 2004. ISSN 0903-1936, 1399-3003. doi: 10.1183/09031936.04.00007104. URL http://erj.ersjournals.com/ cgi/doi/10.1183/09031936.04.00007104.

[56] D S Hui. Impact of severe acute respiratory syndrome (SARS) on pulmonary function, functional capacity and quality of life in a cohort of survivors. Thorax, 60(5):401-409, May 2005. ISSN 00406376. doi: 10.1136/thx.2004.030205. URL https://thorax.bmj.com/ lookup/doi/10.1136/thx.2004.030205.

[57] Margaret S. Herridge, Angela M. Cheung, Catherine M. Tansey, Andrea Matte-Martyn, Natalia Diaz-Granados, Fatma Al-Saidi, Andrew B. Cooper, Cameron B. Guest, C. David Mazer, Sangeeta Mehta, Thomas E. Stewart, Aiala Barr, Deborah Cook, and Arthur S. Slutsky. One-Year Outcomes in Survivors of the Acute Respiratory Distress Syndrome. New England Journal of Medicine, 348(8):683-693, February 2003. ISSN 0028-4793, 1533-4406. doi: 10.1056/NEJMoa022450. URL http://www.nejm.org/doi/abs/10.1056/NEJMoa022450.

[58] Thomas Bein, Steffen Weber-Carstens, and Christian Apfelbacher. Long-term outcome after the acute respiratory distress syndrome: different from general critical illness? Current Opinion in Critical Care, 24(1):35-40, February 2018. ISSN 1070-5295. doi: 10.1097/MCC.0000000000000476. URL http://journals.Iww.com/ 00075198-201802000-00007.

[59] Margaret S. Herridge, Leslie M. Chu, Andrea Matte, George Tomlinson, Linda Chan, Claire Thomas, Jan O. Friedrich, Sangeeta Mehta, Francois Lamontagne, Melanie Levasseur, Niall D. Ferguson, Neill K. J. Adhikari, Jill C. Rudkowski, Hilary Meggison, Yoanna Skrobik, John Flannery, Mark Bayley, Jane Batt, Claudia dos Santos, Susan E. Abbey, Adrienne Tan, Vincent Lo, Sunita Mathur, Matteo Parotto, Denise Morris, Linda Flockhart, Eddy Fan, Christie M. Lee, M. Elizabeth Wilcox, Najib Ayas, Karen Choong, Robert Fowler, Damon C. Scales, Tasnim Sinuff, Brian H. Cuthbertson, Louise Rose, 
Priscila Robles, Stacey Burns, Marcelo Cypel, Lianne Singer, Cecelia Chaparro, Chung-Wai Chow, Shaf Keshavjee, Laurent Brochard, Paul Hebert, Arthur S. Slutsky, John C. Marshall, Deborah Cook, and Jill I. Cameron. The RECOVER Program: Disability Risk Groups and 1-Year Outcome after 7 or More Days of Mechanical Ventilation. American Journal of Respiratory and Critical Care Medicine, 194(7):831-844, October 2016. ISSN 1073-449X, 1535-4970. doi: 10.1164/rccm.201512-2343OC. URL http://www.atsjournals.org/ doi/10.1164/rccm.201512-23430C.

[60] COVID-19 and Rehabilitation, April 2020. URL https://www.ersnet.org/news-and-features/covid-19-blog/ covid-19-and-rehabilitation/.

[61] Christina Jones, Paul Skirrow, Richard D. Griffiths, Gerald H. Humphris, Sarah Ingleby, Jane Eddleston, Carl Waldmann, and Melanie Gager. Rehabilitation after critical illness: A randomized, controlled trial:. Critical Care Medicine, 31(10):2456-2461, October 2003. ISSN 0090-3493. doi: 10.1097/01.CCM.0000089938.56725.33. URL http://journals.Iww.com/00003246-200310000-00006.

[62] Anne E Holland, Ajay Mahal, Catherine J Hill, Annemarie L Lee, Angela T Burge, Narelle S Cox, Rosemary Moore, Caroline Nicolson, Paul O'Halloran, Aroub Lahham, Rebecca Gillies, and Christine F McDonald. Home-based rehabilitation for COPD using minimal resources: a randomised, controlled equivalence trial. Thorax, 72 (1):57-65, January 2017. ISSN 0040-6376, 1468-3296. doi: 10.1136/ thoraxjnl-2016-208514. URL https://thorax.bmj.com/lookup/doi/ 10.1136/thoraxjnl-2016-208514.

[63] Tristan Bonnevie, Francis-Edouard Gravier, Mark Elkins, Johan Dupuis, Guillaume Prieur, Yann Combret, Catherine Viacroze, David Debeaumont, Aurora Robleda-Quesada, Jean Quieffin, et al. People undertaking pulmonary rehabilitation are willing and able to provide accurate data via a remote pulse oximetry system: a multicentre observational study. Journal of physiotherapy, 65(1):28-36, 2019. 